Preprint Version

\title{
The Economic Value of Distributed Storage at Different Locations on an Electric Grid
}

\author{
Wooyoung Jeon*, Alberto J. Lamadrid ${ }^{* *}$, and Timothy D. Mount ${ }^{* * *}$
}

\begin{abstract}
The objective of this article is to analyze the system benefits of distributed storage at different locations on a grid that has a high penetration of renewable generation. The chosen type of distributed storage modeled is deferrable demand (e.g., thermal storage) because it is relatively inexpensive to install compared to batteries and could potentially form a large component of the peak system load. The advantage of owning deferrable demand is that the purchase of energy from the grid can be decoupled from the delivery of an energy service to customers. Consequently, these customers can reduce costs by shifting their purchases from expensive peak periods to off-peak periods when electricity prices are low. In addition, deferrable demand can provide ramping services to the grid to mitigate the uncertainty of renewable generation. The primary economic issue addressed in this paper is to determine how the storage capacity is allocated between shifting load and providing ramping services. The basic economic tradeoff is between the benefit from shifting more load from peak periods to less expensive periods, and reserving some storage capacity for ramping to reduce the amount of conventional reserve capacity purchased.

Our approach uses a new form of stochastic, multi-period Security Constrained Optimal Power Flow (SCOPF) that minimizes the expected system costs for energy and ancillary services over a 24-hour horizon. For each hour, five different levels of wind generation may be realized and these are treated as different system states with known probabilities of occurring. This model is applied to a reduction of the grid in New York State and New England and simulates the hourly load on a hot summer day, treating potential wind generation at different sites as stochastic inputs. The results determine the expected amount and location of conventional generating capacity dispatched, the reserve capacity committed to maintain operating reliability, the charging/discharging of storage capacity, and the amount of potential wind generation spilled. The results show there are major differences in how the deferrable demand at two large load centers, Boston and New York City, is managed, and we provide an explanation for these differences.
\end{abstract}

Keywords: Electricity Markets, renewable energy sources, energy storage systems, thermal storage. JEL L94, Q48, D40

http://www.doi.com

\section{INTRODUCTION}

Although increasing the dependence on Renewable Energy Sources (RES) for generating electricity is expected to lower operating costs, the expected savings may not be fully realized due to the operational challenges caused by the inherent variability of RES. One effective way to mitigate this uncertainty is to use storage capacity as a buffer. For example, one could collocate batteries at wind farms to

*Department of Economics, Chonnam National University, Gwangju, 61186, South Korea

${ }^{* *}$ Corresponding author. Department of Economics and Department of Industrial and Systems Engineering, Lehigh University, 451 Rauch Center, Bethlehem, PA, 18015. E-mail: ajlamadrid@ieee.org

${ }^{* * *}$ Dyson School of Applied Economics and Management, Cornell University, Warren Hall, Ithaca, NY, 14853 
provide a source of generation that is smoother and more predictable. However, having batteries dedicated solely to this purpose is relatively expensive. In contrast, distributed storage located at load centers can mitigate the variability of RES and also modify load profiles, and in particular, reduce the peak system load and congestion on the grid. Consequently, distributed storage can lower the amount of Conventional Generating Capacity (CGC) committed for reserves and ramping and also the amount of installed CGC needed to ensure generation adequacy for the grid. The basic economic questions addressed in this paper are (1) how is the capacity of distributed storage allocated between providing ramping services and shifting load from peak to off-peak periods, and (2) what are the implications of this allocation on total system costs, including the capital cost of installed CGC.

Ramping services are needed because of the natural variability of RES and the difficulty of forecasting generation from RES accurately. This uncertainty increases operating costs and steps have been taken in some regions to internalize the associated ramping costs (e.g., Wang and Hobbs. 2016), but even if this is done, congestion on the grid can still prevent CGC and RES at remote locations from participating effectively in the market. When suitable incentive mechanisms are provided for installing storage capacity, the storage can improve the utilization of all generation assets on the grid. The economic and environmental value of using storage in the wholesale market is clearly recognized in the literature (e.g., Sioshansi and Denholm, 2010; Denholm et al., 2013, RTO Insider, 2016), and recently, attention has also been directed to using storage for regulation due to its rapid response capabilities (Parkinson, 2017; Washington Post, 2017). In general, the actual way storage capacity is used is affected by local conditions on the grid, and this determines the system benefits derived from the storage at a specific location. The overall implication is that the benefits derived from storage at different locations vary because the storage is used differently at different locations. Understanding the causes of these differences is a central theme for this paper.

We have argued in other papers (Jeon et al. 2015) that deferrable demand ${ }^{1}$ is an attractive form of distributed storage because it is typically less expensive than batteries. Examples of deferrable demand include (1) Thermal Storage (TS) for space heating/cooling, (2) electric water heaters, and (3) smart-charging of the batteries ${ }^{2}$ in Electric Vehicles (EVs). EVs can improve the management of the grid by charging during low demand periods with excess generation from RES, reducing the spillage of this resource, and, if vehicle-to-grid capabilities are supported, discharging when generation from RES is less than expected. TS works in a similar way to EVs but its potential effect is much larger (e.g., Xu et al. 2013). The stored TS energy can be used to reduce the system peak by, for example, displacing the compressors used for air-conditioning when the load on the grid is high. Furthermore, the potential for TS is large because the amount of energy used for heating and cooling accounts for roughly 40 percent of total energy consumption in the residential and commercial sectors (39 quadrillion British Thermal Units in 2016 for the US, (EIA, 2015, 2017)). There are, in fact, numerous recent contributions to the literature that recognize this potential and focus on the control of thermostatic load and the possibility of coupling it with RES (e.g., Callaway and Hiskens, 2011; Pourmousavi et al., 2014).

Past research has shed light on the efficiency issues raised by, for example, the widespread use of flat-rate structures for retail rates and the perverse incentives that they provide for investing in deferrable demand (Simshauser and Downer. 2016). In fact, experience with regulations that increase the responsiveness of demand by using real-time prices shows that this is the most promising way to develop two-sided markets (e.g., Bushnell et al., 2009; Chen and Kleit. 2016), and there is a large literature looking at the welfare gains from real-time prices (e.g., Borenstein, 2005, Faruqui et al. 2014) and also from block pricing (e.g., You and Lim, 2017). Overall, tariffs that are reflective of the

\footnotetext{
${ }^{1}$ Deferrable demand makes it feasible to decouple the purchase of energy from the grid from the delivery of an energy service to customers. Customers still get the same energy services delivered when they need them but the timing of purchases from the grid is flexible and can respond to real-time conditions on the grid.

${ }^{2}$ Although these are conventional batteries, they were purchased to provide transportation rather than services to the grid, and as a result, smart-charging/discharging to support conditions on the grid can be considered to be a form of deferrable demand.
} 
true system costs lead to gains in welfare, and in this article, our focus is on how to reduce the total system costs. Note that information available in the prices can help improve the forecasting of other variables of interest, notably the load (Forbes and Zampelli, 2014). The effects on lowering retail rate structures will be addressed in future work. One reason for this is that we conclude our article by questioning whether minimizing the expected operating costs during peak periods, and ignoring capital costs, leads to long-run efficiency in the use of storage capacity.

The specific objective of this work and our main contribution is to determine the value of deferrable demand at different locations. The analysis uses a stochastic form of multi-period Security Constrained Optimal Power Flow (SCOPF) that maximizes the expected social surplus for operations over a 24-hour period. This model assumes that a System Operator (SO) determines how all generating capacity is committed and the charging/discharging profiles of deferrable demand (EVs and TS). We simulate the daily operations of the grid using a reduced network representing New York State and New England with different assumptions about the amount of deferrable demand that is available. This type of application leads naturally to differences in the shadow prices at different locations. Since each shadow price represents the expected marginal cost of delivering energy at a specific location, it determines, to a large extent, the optimum use of any deferrable demand at that location. Our main empirical results show that there are major differences in the use of deferrable demand at two large load centers, representing Boston and New York City. We focus on wind energy and the coupling effects it has with deferrable demand, due to the diurnal pattern of this resource and the characteristics of the location for our empirical application, the Northeastern US. Our analytical approach and conclusions can inform plans for other regions with similar prospective levels of wind generation to our empirical area of study. These results have economic policy implications for the design of electricity tariffs and for improving the net social benefits of the grid (e.g., Woo and Seeto. 1988; Hobbs, 1991; Borenstein 2007). However, the main practical conclusion from the analysis is to demonstrate that distributed storage (i.e., deferrable demand at load centers) can be an effective way to provide ramping services to the grid to mitigate the inherent uncertainty of the generation from wind farms on the grid. It is not necessary to colocate storage at the wind farms.

The remainder of the article is organized as follows. Section 2 provides a description of the analytical framework and explains the spatial characteristics of inputs for the model. Section 3 presents the information exchanges that define the market and operations on the grid, and the physical specifications of deferrable demand for TS and EVs. Section 4 presents the empirical results for five different cases for an application in which a SO optimizes operations on the grid and the management of deferrable demand. Section 5 concludes and provides suggestions for further research.

\section{FORMULATION AND DATA}

This work belongs to the literature on integrating RES into grid operations, focusing on the problem from the viewpoint of the SO (e.g., Hirth, 2015). Most of this recent literature uses either stochastic programming (e.g., Arroyo and Galiana, 2005) or robust optimization (e.g., Bertsimas et al., 2013) for the simulation analysis. The high computational requirements for these methods have prompted a discussion of novel solutions approaches (e.g., Siano et al., 2012) or approximations to the distribution of the uncertain parameters (e.g., Warrington et al. 2012). This article uses a unique, probabilistic, multi-period Security Constrained Optimal Power Flow (pS-SC-OPF). The SO's objective is to maximize the total expected welfare of the participants in the system associated to the provision of energy subject to a set of economic criteria focused on reliability, and the technical constraints of the system. A particularly relevant contribution of this model is the determination of shadow prices of electricity that internalize the variability and uncertainty from RES (Lamadrid et al., 2015). The main differences between our model and other stochastic formulations used to study similar problems can be summarized in four areas:

1. The distinction between different classes of uncertainty in the system. The first class is related 
to events with a low probability of occurrence (e.g., an outage due to a "tree strike" on a transmission line, or contingencies). The second class is related to events that have high probability of occurrence (e.g., generation from RES drastically changing due to clouds passing in the case of solar energy, or states). The uncertainty from events in both classes affects system operations and the overall expected cost. In this case, an information layer (e.g., a Supervisory Control and Data Acquisition System, SCADA) can provide the SO with the information needed to re-dispatch units. Our framework determines an optimal dispatch assuming that the SCADA system relies on trustworthy information (Queiroz et al., 2013)

2. The management of demand (Wirl, 2000; Palensky and Dietrich, 2011), and its valuation in the consumer surplus calculation at the Value of Lost Load (VOLL) (Lawton et al., 2003). This provides an economic mechanism for evaluating reliability by allowing load to be shed in some, typically low probability, states instead of purchasing additional reserve capacity. The interaction between active demand and low probability events affects system operations and improves the survivability of the system, compensating the consumers for the interruption in their service

3. The determination of ancillary services and ramping costs is part of the solution to the SO problem. The endogenous calculation of different types of reserves determines the amount of committed capacity needed to mitigate the variability from RES and the composition of generation in each system state. The total amount of capacity committed on peak load days in the summer determines the total capital cost of maintaining generation adequacy (Cuomo 2014)

4. The modeling of energy storage systems (ESS), including power and energy constraints. The flexibility of ESS, such as deferrable demand, provides ramping services to mitigate the variability of RES in a similar way to storage collocated at wind or solar farms. At the same time, distributed ESS reduces the flows and congestion on the network during system peaks and the amount of installed generating capacity needed for adequacy (Kraning et al., 2014)

Our model can comply with the $n-1$ operating criterion, as mandated by the reliability standards of the North American Electric Reliability Corporation (NERC) TOP-004-2 and TPL-001-4 (NERC, 2017), if load shedding is not allowed when contingencies occur. However, by allowing load shedding at a high VOLL, it is possible to identify the economic tradeoff between shedding less load in a low-probability contingency and the certain cost of purchasing more reserve capacity.

\subsection{Model}

Our analysis is based upon a stochastic formulation of the costs and benefits of operating the electric grid, including the ancillary services. The problem is a mixed integer quadratic program (MIQP). This model is formulated in the open source MATPOwER Optimal Scheduling Tool package. A simplified formulation of (MOST) is presented in the Appendix. The objective function of the SO is the probability weighted sum of the producer and consumer surplus, consistent of seven components: A.1) the cost of energy delivered in the realized states, $f_{p}(p)$, and the cost of deviations from contracts (re-dispatching the system, or INCs and DECs), $f_{p}\left(p_{+}, p_{-}\right)$; (A.2) The benefits demand receives from having their load served (no load shedding) and possible load response programs, $f_{d}\left(d, d_{+}, d_{-}\right)$; (A.3) the cost of delivering reserves to maintain operational reliability, $f_{r}\left(r_{z}, r_{+}, r_{-}\right)$; A.4 the ramping costs incurred in the period-to-period transition, $f_{\delta}(p)$; A.5. the cost of procuring load-following reserve to transition over time, $f_{\mathrm{ff}}\left(\delta_{+}, \delta_{-}\right)$; (A.6) the cost of the energy stored, $f_{s}\left(p_{\mathrm{sc}}, p_{\mathrm{sd}}\right)$; and (A.7) the cost of committing units, $f_{\mathrm{uc}}(v, w)$. The objective function is subject to the balance between supply and demand, contractual arrangements, and all of the constraints of the network. The constraints of the problem are grouped also in seven component categories: (a) the full set of equality constraints, 
equation A.8, e.g., power balance equations for supply and demand, Kirchhoff's laws; (b) the set of operational inequality constraints, equation (A.9), e.g., piecewise linear capability curves; (c) the set of constraints for re-dispatching and deviations from contracts for all generators and demand, equation A.10; (d) the ramping limits for contingencies, equation (A.11), i.e., low probability events; (e) the ramping limits for load following, equation (A.12) i.e., high probability events; (f) limits on the storage units, A.13; and (g) constraints related to unit commitment of the generating units, equation (A.14).

The nodal levels of demand are fixed blocks for each time period at the substation level, and they are specified as negative injections valued at the VOLL per MWh. Since the model determines the load not served (LNS) endogenously, the system operator has an additional option for managing the physical constraints on the network and avoiding infeasible solutions. However, the high cost of this option typically limits its utilization to system states that have a low probability of occurring, such as contingencies.

The objective function minimizes the expected operating costs plus the expected cost of LNS for a 24-hour horizon. Two points about the objective function: (1) the operating costs correspond to the sum of the true marginal cost of generation for each unit dispatched, plus the costs of acquiring reserves and the wear-and-tear of ramping. Typically, the nodal price paid to generators for the energy dispatched at a substation is higher than the true marginal cost for some units. (2) Our objective is equivalent to maximizing the (minimizing the negative) expected total daily social surplus because the consumer surplus corresponds to the daily sum of the load served times (VOLL - Nodal Price) at all substations, and the supplier surplus corresponds to the daily sum of the generation times (Nodal Price - True Marginal Cost for all Units) minus the daily cost of reserves and ramping at all substations (since the optimization uses a DC network, there are no losses). Consequently, the total daily social surplus equals the expected load served times VOLL minus the expected cost of generation, reserves and ramping summed over the 24-hour horizon.

Moreover, by allowing LNS, this objective function is less stringent than the standard criterion used by system operators because it does not ensure that load is served in all contingencies considered. Nevertheless, the typical system operator's objective function is not stochastic, and consequently, it does not consider the possibility of different states for the intact system (e.g., different levels of potential wind generation). In our stochastic optimization, it may well be very expensive to cover a low-probability contingency in a low-probability system state that has, for example, a low level of potential wind generation.

\subsection{Geographical Differentiation}

One of the main contributions of our approach is the specific modeling of the endogenous amount of different types of reserves, including the cost of contingency and load following, as well as the wear-and-tear (ramping) costs (EPRI, 2001b a) differentiated by their ability to deliver services across the grid (an ability sometimes called deliverability). The terms $C_{R+}(\cdot), C_{R_{-}}(\cdot)$ in $\mathrm{A} .3$ correspond to the cost of contingency reserves to deal with low probability cases (up and down). The terms $C_{\delta+}(\cdot), C_{\delta_{-}}(\cdot)$ in $\mathrm{A} .5$, the load following reserves, deal with inter-temporal changes. Most markets in the U.S. co-optimize energy and a level of predetermined reserves. The main implication of including these costs as part of the objective function instead of as constraints in the system is that the optimal level of reserves is endogenously determined, based on system conditions.

Due to the fact that the reserves are determined at the nodal level (in fact, at the generator level, for each $i$ ), the deliverability of reserves takes into account the network constraints of the electrical system. Moreover, the endogenous calculation of the reserves in our inter-temporal model allows to better value the contributions of storage to the overall system welfare calculation. The main implication of this formulation approach is that it allows for spatial diversity in the provision and demand of energy services. 
Figure 1: Location of Nodes in the Reduced System

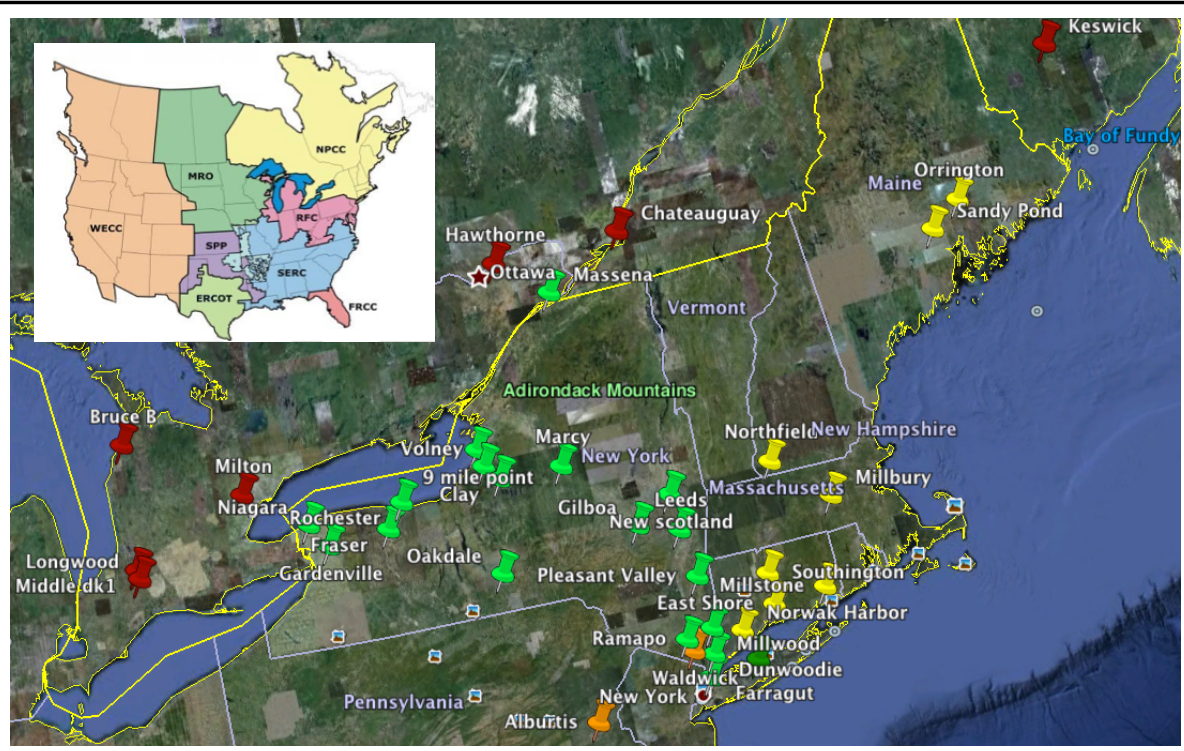

\subsection{Network model and Stochastic Data}

We use a reduction of the Northeast Power Coordinating Council (NPCC) (Allen et al., 2008). Figure 1 shows the locations of the nodes in the reduced system and the NPCC region in the NERC reliability entities from before 2010. This reduced system has 36 buses, 19 of them in New York, shown in green in Figure 1, and nine in New England, shown in yellow in Figure 1 We update the generation information, to include the heat rate and ramping characteristics from 693 generators in the U.S. system in 2009. The details of the installed capacities and the network for this northeastern test network (NETnet) are presented in Lamadrid et al. (2014).

For the wind locations, we perform a principal component analysis to assign the 66 sites in New York and 113 sites in New England from the Eastern wind integration and transmission study, EWITS (NREL, 2010) to the available nodes in the NETnet network. Using a cutoff of explaining 90 percent of the cumulative variance of wind speeds, we specify nine sites in New York state and seven in New England. We use the same EWITS data to transform the 10-minutes simulated data to hourly values that are then used to estimate auto regressive moving average models with exogenous variables (ARMAX) for temperature, demand and wind speed. Details of the ARMAX variables for the fit obtained are presented in Jeon et al. (2015).

\section{INFORMATION FLOWS AND DEFERRABLE DEMAND}

Recent literature on smart grid modeling has focused on how to use the nodal prices for resiliency management (Guan and Kezunovic, 2013) and the overall architecture to enable the participation of demand resources (Rahimi and Ipakchi, 2010). In our implementation, two distinct types of deferrable demand are specified, plus energy storage systems (ESS) collocated at the wind sites. The communication and information exchanges are summarized in Figure 2.

The system operator characterizes the stochastic inputs, including the distributions of possible outcomes for loads and renewable energy sources, and the information on the progression (e.g., the transitions or trajectories) over a defined time horizon. Even though the underlying real distribution of these stochastic inputs is not known, the model discretizes over a set of finite states with specified probabilities. Generators submit offers to sell energy and reserves, and aggregators submit bids to buy energy to meet their customers demand for energy and to manage distributed storage. The model 
Figure 2: Flows of Energy and Information in the Cyber-Physical System

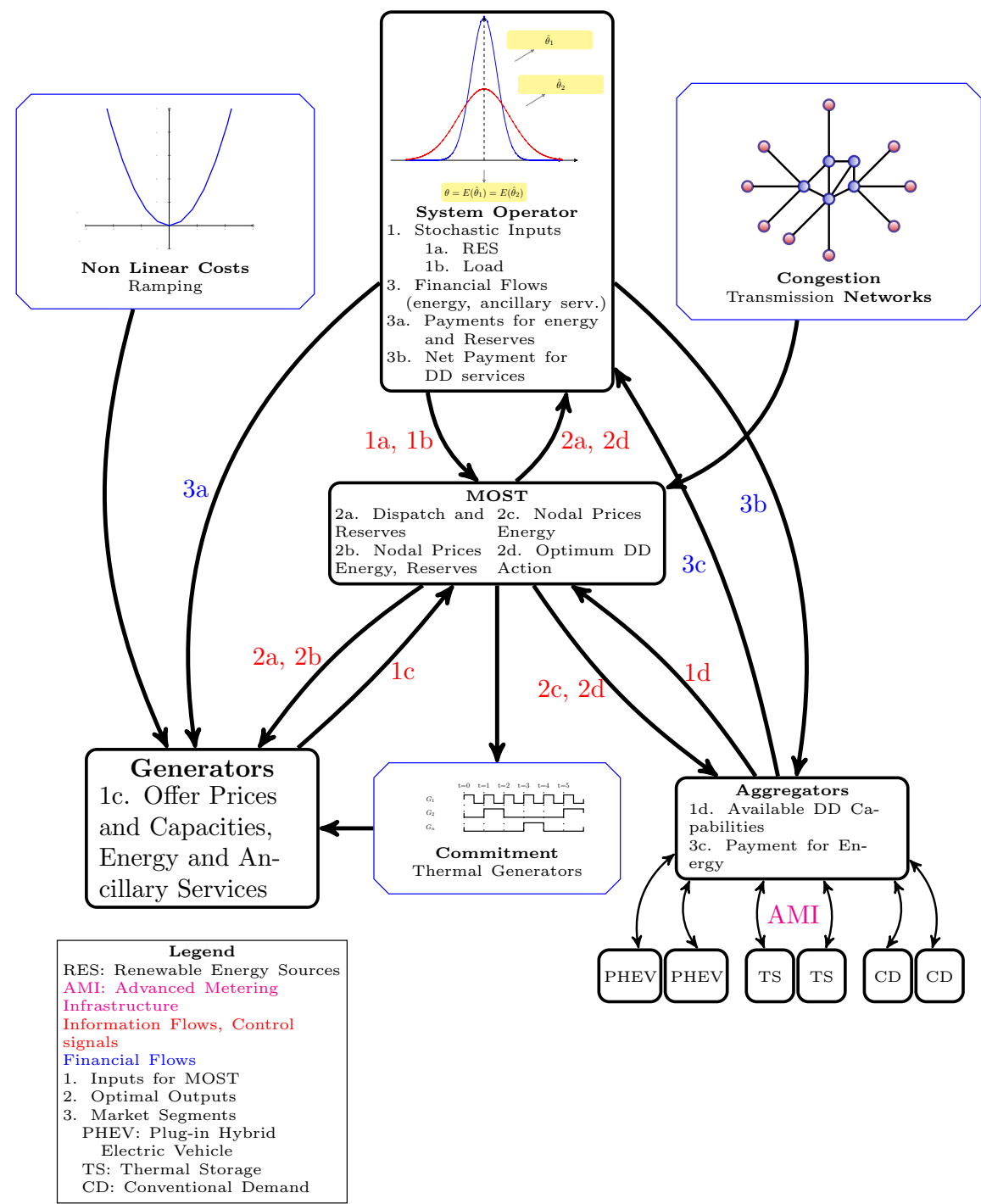

optimizes by minimizing the expected operating costs over the time horizon which is the deterministic equivalent formulation of social welfare. The results of the optimization determine, for every system state, the dispatches of energy and ancillary services (different types of reserves), the shadow prices for energy and reserves and the charging/discharging of deferrable demand. The payments to/by all participants are then determined by the market payments for the different services provided/used.

We assume that there are aggregators of customers who participate in the market and manage the distributed storage capabilities. Storage capabilities are not limited to Battery Energy Storage Systems (BESS) such as chemical batteries. In particular, we make use of thermal storage, (e.g., ice batteries) to substitute for the air-conditioning used for space cooling. This is an effective alternative, and in summer-peaking regions, it provides an economical method to reduce the peak system load. The flexibility provided by thermal storage to decouple the purchase of electricity from the delivery of the energy service is an example of deferrable demand (DD). DD includes many type of technologies that behave in a similar manner to an inventory management problem, or a battery. Some well established examples include water heaters and water pumping for municipal reservoirs. Even though electric vehicles have batteries, they behave like DD because charging the batteries is decoupled from 
Figure 3: Temperature/Non-Temperature Sensitive Demand (TSD/NTSD)

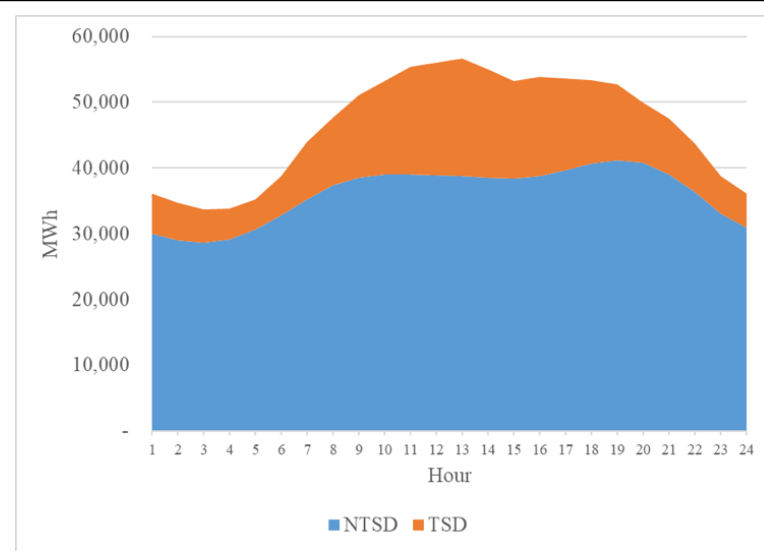

the delivery of transportation services. The decoupling of energy purchases from the delivery of energy services makes it feasible to deliver energy services without creating any inconvenience to end users. For example, heating water and charging the battery of an electric car in the middle of the night, when wind energy is available and electricity prices are relatively low, allows customers to have a hot shower in the morning and commute to work.

Generally, the flexibility that some consumers have in their usage patterns can be used to improve the utilization of RES. However, this flexibility is usually associated with some losses akin to a battery's round-trip inefficiency. Therefore, customers with DD capabilities have to purchase more electricity than customers without these capabilities who have identical levels of demand. This is another reason why DD is substantially different from a standard demand response (DR) program. The role of DR programs, like turning up the thermostats for air conditioning, is to use less electricity by reducing the energy services delivered. Even though it is sensible to encourage energy efficiency, reducing the total amount of energy purchased is not a sensible goal for policy. In fact, with a higher penetration of RES, some spillage is likely to occur during times of low demand. Implementing DD technologies that can use this surplus energy can help to offset the roundtrip inefficiency of DD. Hence, a better policy goal is to reduce the effect of externalities (e.g., reducing total emissions from fossil fuels) and still supply the energy services demanded by customers.

\subsection{The Specifications for Thermal Storage}

In Lamadrid et al. (2013) we defined DD for thermal services. We first estimate the amount of temperature-sensitive demand (TSD), to serve as the potential amount of energy that can be deferred by thermal storage and its limits. We estimated TSD and non temperature-sensitive demand (NTSD) from a base demand level as shown in Figure 3 , and used hourly TSD level to restrict the amount of energy that can be deferred each hour.

This specification has been refined and it now assumes a 16 percent penetration of the total potential cooling load (based on the estimated temperature-sensitive-load, TSL). The ice building and melting rates vary depending on the number of chillers installed with the thermal storage. The hourly ice building rate is specified to be 12 percent and the hourly ice melting rate is 16.7 percent of the total storage capacity (EVAPCO, 2007, Hunt et al., 2010). The storage efficiency is 86 percent, based on an average energy efficiency ratio (EER) of 8.8, contrasting with an average EER of 10.2 for conventional air conditioning. Table 1 summarizes the specifications used for Temperature and Non-Temperature Sensitive Demand (TSD/NTSD), as well as for the thermal storage considered. 
Table 1: Summary of Specifications and Capacities for Thermal Storage

\begin{tabular}{lr}
\hline Item & Specification (units) \\
\hline Target Aggregated TS Capacity & $34(\mathrm{GWh})$ \\
Total Aggregated TSD in the given & $249.75(\mathrm{GWh})$ \\
day & \\
Penetration Rate & 13.61 (percentage) \\
TS Capacity of Benchmark Prod- & $30,000(\mathrm{kWh})$ \\
uct(Calmac) & \\
Ice Building Power & $3,600(\mathrm{~kW})$ \\
Ice Melting Power & $5,000(\mathrm{~kW})$ \\
Ice Building Power Rate & $12($ percentage) \\
Ice Melting Power Rate & 17 (percentage) \\
Storage Efficiency & 86 (percentage) \\
\hline
\end{tabular}

\subsection{The Specifications for Electric Vehicles}

In addition to thermal storage, we modeled the DD for electric vehicles (EV), specifically a GM Chevrolet Volt 2013. The Volt's battery uses lithium-ion technology with a usable energy capacity of $10.8 \mathrm{kWh}$. The average round-trip efficiency of these batteries is 90 percent (EAC, 2008, Keller et al. 2008), and we specified two types of charging levels: Level 1 charging, delivering up to 1.44 $\mathrm{kW}$ and level 2 charging, delivering up to $7.68 \mathrm{~kW}$ according to existing technology (Massachusetts Division of Energy Resources, 2000). We assume a 70/30 percent penetration of level-1/level-2 chargers, respectively. The first generation Volt was offered until 2015, and now the second generation is available. The main difference in terms of the energy storage between the first and the second generation Volt is that the newer model is equipped with a battery whose capacity is $18.4 \mathrm{kWh}$, which is 11.5 percent larger compared to the first generation. Applying the state of charge up to 65 percent of battery capacity, its possible driving range with full charge is approximately 48 miles. Even though battery capacity increased, the vehicle price before government incentives dropped by 14.7 percent from $\$ 39,995$ to $\$ 34,095$ in 2018 due to a sharp decline in lithium ion battery prices in recent years. Assuming that 20 percent of the total registered vehicles in New York and New England (NY-NE) are converted to EVs, the total energy capacity of the storage amounts to 34GWh. These 3,138,525 cars are distributed among the five major demand centers in our system in proportion to the electric load at each center. The average driving distance is specified to be 27.2 miles, corresponding to "center city" commuting patterns (Parsons and Douglas. 2000). In contrast, the rural and suburban distances are 36.9 and 28.8 miles respectively (Davis et al. 2013). The hourly number of vehicles charging at home is based on the 'Commuter-at-Home Profile' (Valentine et al., 2011).

\section{RESULTS OF THE CASE STUDY AND DISCUSSION}

In this section we present the simulation results for the following five cases:

i. Case 1: No Wind, base case

ii. Case 2: Case $1+32 \mathrm{GW}$ of Wind Capacity at 16 locations, as specified in Lamadrid et al. (2013)

iii. Case 3a: Case $2+34 \mathrm{GWh}$ of Thermal Storage (TS) at 5 demand centers

iv. Case 3b: Case $2+34 \mathrm{GWh}$ of Electric Vehicle (EV) batteries at 5 demand centers

v. Case 3c: Case $2+17 \mathrm{GWh}$ of both TS and EV at 5 load centers 
Note that Cases $3 \mathrm{a}, 3 \mathrm{~b}$ and $3 \mathrm{c}$ have the same total amount of deferrable demand, $34 \mathrm{GWh}$, to be able to compare across these cases. In the growing literature about the effects of cycling on conventional generation for ramping (Agan et al., 2008; Lefton and Hilleman, 2011; Kumar et al. 2012, Lew et al. 2012), there are three main sources of costs identified: (1) Decreased efficiency and higher heat rates, (2) Increased operation and maintenance (O\&M) costs and (3) Increased probability of outages and equipment forced outage rates (EFOR). The model includes these costs and generators are compensated via two mechanisms. The first mechanism pays the generators in advance for the capacity required to cover the largest deviations (up and down) amongst the high probability states (i.e., intact states with different levels of potential wind generation). Since this form of payment is similar to the capacity payments for low probability cases (i.e., when some equipment fails), usually denoted as contingency reserves (CR), we call this ramping reserves (RR).

Table 2: Ramping Reserve Costs

\begin{tabular}{lrrrrr}
\hline Fuel & coal & natural gas & oil & hydro & nuclear \\
\hline Rp.R. $^{a}$ & 30 & 10 & 10 & 60 & 60 \\
\hline
\end{tabular}

${ }^{a}$ Ramping Reserve costs (\$t/MW).

The values used in our calibration for ramping costs are shown in Table 2 The mean prices for 10-minute spinning reserve range from $\$ 2.54 / \mathrm{MWh}$ to $\$ 14.15 / \mathrm{MWh}$ among U.S. Independent System Operators (ISOs) in 2014 (Zhou et al. 2016). Hence, we use \$10/MWh for basic ramping reserve offer price for flexible units like natural gas and oil. The second mechanism compensates generators for the out-of-pocket cost of wear-and-tear based on the changes in dispatch from one time period to the next, (see equation A.4 ) valuing upward and downward deviations symmetrically using a quadratic coefficient as shown in (1).

$$
\sum_{i \in I^{0}} a_{r}\left(p^{i t 0}-\hat{p}^{i, t-1,0}\right)^{2}
$$

Table 3 summarizes the results for the peak load hour (hour 15 is 3PM) and it shows the expected and maximum levels of dispatch of conventional generation, deferrable demand, and wind generation for the 12 possible system states, consisting of 4 intact states and 8 contingency states. Table 3 also includes two financial metrics of the expected daily costs: (i) the expected cost of generation, associated mainly with the fuel and O\&M costs (the first term of equation (A.1) in the Appendix); and (ii) the expected total operating cost, the sum of the expected cost of generation plus the ancillary services provided. The cost of ancillary services include the cost of re-dispatching (the second and third term of equation (A.1) in the Appendix); the contingency reserve costs (equation A.3 in the Appendix); the ramping cost (equation A.4 in the Appendix); and the load following ramping reserve (equation $A .5$ in the Appendix). In other words, the difference between the expected generation cost and expected total operating cost corresponds to the expected cost of ancillary services and ramping. The columns correspond to the five cases (e.g., $\mathrm{c} 1$ is Case 1, and $\mathrm{c} 2-\mathrm{c} 1$ is the difference between Case 2 and Case 1, etc.). For the physical metrics (MW, MWh), we focus on the peak hour due to its importance for determining the amount of installed generating capacity, and the associated capital cost, needed to ensure system adequacy. Comparing the five cases, the savings in operating cost come from (1) displacing fossil fuels with wind generation and (2) by using DD to reduce ramping costs. In addition, savings in the capital cost of installed conventional generating capacity can be achieved by (1) reducing the peak system load, and (2) using DD to provide ramping services.

The size and composition of these savings are substantially different in the different cases. For example, consider E[Electric Energy Delivered]. The results show that the amounts in Cases 1 and 2, when there is no DD, are the same, and in Case 2, wind generation displaces 2,614 MWh of the conventional generation in Case 1. In all three cases with DD (3a, 3b and 3c), E[Wind Generation] increases compared to Case 2 because the DD makes it economical to spill less of the potential 
Table 3: Summary of Results

\begin{tabular}{|c|c|c|c|c|c|}
\hline & $\mathrm{c} 1$ & $\mathrm{c} 2-\mathrm{c} 1$ & $\mathrm{c} 3 \mathrm{a}-\mathrm{c} 2$ & $c 3 b-c 2$ & $\mathrm{c} 3 \mathrm{c}-\mathrm{c} 2$ \\
\hline Peak Hour & 15 & 15 & 15 & 15 & 15 \\
\hline \multicolumn{6}{|c|}{ Expected Peak Outcomes (MWh) } \\
\hline $\mathrm{E}[$ Load Served $]$ & 61,811 & 0 & $-2,973$ & 336 & $-1,367$ \\
\hline E[Load Not Served $]$ & 0 & 0 & 0 & 0 & 0 \\
\hline $\mathrm{E}[$ Conventional Generation] & 58,423 & $-2,614$ & $-3,409$ & -18 & $-1,672$ \\
\hline E[Wind Generation] & 0 & 2,614 & 435 & 354 & 305 \\
\hline $\mathrm{E}$ [Exogenous Imports] & 3,388 & 0 & 0 & 0 & 0 \\
\hline E[Electric Energy Delivered] & 61,811 & 0 & $-2,973$ & 336 & $-1,367$ \\
\hline $\mathrm{E}[$ Deferrable Demand $]$ & 0 & 0 & 2,974 & 1,286 & 2,178 \\
\hline \multicolumn{6}{|c|}{ Expected Daily Cost $(\$ 1,000 /$ day $)$} \\
\hline $\mathrm{E}[\text { Generation Cost }]^{a}$ & 49,982 & $-12,869$ & $-1,261$ & 848 & -206 \\
\hline $\mathbf{E}[\text { Total Operating Cost }]^{a}$ & 50,848 & $-11,410$ & $-2,480$ & 509 & $-1,226$ \\
\hline \multicolumn{6}{|l|}{ Maximum Outcomes (MW) } \\
\hline All Load Served & 61,812 & 0 & $-5,606$ & 0 & $-2,825$ \\
\hline Conventional Load Served & 61,812 & 0 & 0 & 1,622 & 811 \\
\hline Deferrable Demand & 0 & 0 & 5,649 & 1,622 & 3,636 \\
\hline Conv. Generation, Intact States & 58,424 & $-1,603$ & $-4,342$ & 0 & $-2,572$ \\
\hline Conv. Generation, All States & 59,570 & $-1,604$ & $-5,420$ & 0 & $-2,825$ \\
\hline Wind Generation & 0 & 6,088 & 3,135 & 3,306 & 2,515 \\
\hline LF Ramp-Up & 27 & 1,654 & $-1,531$ & 83 & $-1,557$ \\
\hline LF Ramp-Down & 549 & 3,385 & $-3,716$ & -482 & $-2,868$ \\
\hline Contingency Ramp & 1,146 & 2,490 & $-3,399$ & 83 & $-2,490$ \\
\hline
\end{tabular}

$a_{\$ 1,000 / \text { day }}$

wind generation by providing inexpensive ramping services. In addition, both E[Load Served] and $\mathrm{E}$ [Conventional Generation] are lower than Case 2 in Cases 3a and 3c with DD from thermal storage (TS). It should be noted here that the TS is assumed to displace some of the existing load for air conditioning. In contrast, electric vehicles $(\mathrm{EV})$ are assumed to be a new type of load, and the savings in transportation costs for customers would come from purchasing less gasoline. Furthermore, the DD from EVs comes from "smart charging" only, and there is no vehicle-to-grid discharging. Consequently, the E[Load Served] in Case 3b with EVs only is actually slightly higher than it is in Case 2, because charging the EVs in high-wind states displaces some of the down-ramping services that would otherwise be provided by conventional generating units. Most of the charging of the batteries in EVs is done at night when prices are relatively low.

In a traditional planning process for an electric grid, the maximum annual load determines how much installed generating capacity is needed for system adequacy. In our analysis, the equivalent metric is the maximum amount of conventional generating capacity that is committed for dispatch and reserves, i.e., the Max[Conv. Generation, All States] in Table 3 . Adding 32 GW of wind capacity in Case 2 reduces Max[Conv. Generation, All States] by only $1.6 \mathrm{GW}$ (5 percent of the installed capacity). The main reason for this small reduction is the large increase in the reserve capacity needed for load following (LF) and contingencies. An extra $4.1 \mathrm{GW}$ of installed capacity for reserves is needed in Case 2 for LF Ramp-Up plus Contingency Ramp. 
With the addition of TS in Case 3a, the Max[Conv. Generation, All States] is reduced by an additional $5.4 \mathrm{GW}$ compared to Case 2. This is accomplished by reducing the Max[All Load Served] by $5.6 \mathrm{GW}$ and the reserve capacity by $4.9 \mathrm{GW}$. Note that these two reductions are not additive because they do not occur in the same system state. The difference between Max[Conv. Generation, All States] and E[Conventional Generation] is a better measure of reserves, and this value is $2.2 \mathrm{GW}$ in Case 2 and only $0.15 \mathrm{GW}$ in Case 3a. In other words, most of the reserve capacity required for ramping and contingencies in Case $3 \mathrm{a}$ is provided by charging and discharging TS. In contrast, having only EVs in Case $3 b$ has no effect on the Max[Conv. Generation, All States] compared to Case 2, and in this respect, the major source of savings from TS in Case 3a can not be replicated with EVs unless the capabilities of vehicle-to-grid discharging are supported. The results for Case $3 \mathrm{c}$ with a mixture of TS and EVs are, as expected, roughly halfway between the results for Case $3 \mathrm{a}$ and Case $3 \mathrm{~b}$.

Table 4 summarizes the incremental capital costs of installed conventional generation and DD for the five cases. The assumptions for calculating these costs are included in the footnotes of Table 4. The cost of TS assumes that the DD storage is a supplement to an existing central air conditioning system, and the cost of an EV is the incremental cost above an equivalent gasoline vehicle. The savings in capital costs from TS in Cases $3 \mathrm{a}$ and $3 \mathrm{c}$ are proportional to the reductions in the Max[Conv. Generation, All States], and these savings in Case 3a are twice as big as the capital cost of the TS. The net savings of $\$ 4.7$ million in Case 3a from adding TS is 1.67 times larger that the savings from adding wind capacity, at no cost, in Case 2. Since the EVs in Case $3 \mathrm{~b}$ do not reduce Max[Conv. Generation, All States], there are no savings to offset the full cost of the (expensive) EV batteries. In Case 3c, the net savings from the TS is not sufficient to cover the capital cost of the EV batteries. The overall conclusion in this example is that TS is the only effective way to reduce the combined capital cost of installed generating capacity and storage.

Table 4: A Comparison of the Incremental Capital Costs

\begin{tabular}{|c|c|c|c|c|c|}
\hline & $\mathrm{c} 1$ & $(\mathrm{c} 2-\mathrm{c} 1)$ & $(\mathrm{c} 3 \mathrm{a}-\mathrm{c} 2)$ & $(\mathrm{c} 3 \mathrm{~b}-\mathrm{c} 2)$ & $(\mathrm{c} 3 \mathrm{c}-\mathrm{c} 2)$ \\
\hline \multicolumn{6}{|l|}{ Capital Cost $(\$ 1000)$} \\
\hline Conv. Generating Units ${ }^{a}$ & 104,844 & $-2,821$ & $-9,379$ & 0 & $-4,971$ \\
\hline Deferrable Demand EV ${ }^{b}$ & - & - & - & 9,321 & 4,661 \\
\hline Deferrable Demand $\mathrm{TS}^{c}$ & - & - & 4,643 & - & 2,322 \\
\hline Total Capital Cost & 104,844 & $-2,821$ & $-4,736$ & 9,321 & 2,012 \\
\hline
\end{tabular}

\subsection{Ramping and Deferrable Demand}

Figure 4 shows how DD capabilities affect the amount of ramping provided by oil generators and the amount of wind generation by comparing Case 2, which has no DD, and Case 3c, which has DD from both TS and EVs. These two types of generation are selected to illustrate the primary ways that DD is used to reduce operating costs. The first plot shows the hourly ranges of dispatch for oil generators in the two cases. The solid lines, marked with Xs, are the expected levels of dispatch, and the shaded areas show the maximum and minimum levels in the different system states. The maximum over the 24 hours corresponds to the maximum capacity committed. The grey ranges, representing Case 2 , are generally much larger than the orange ranges, representing Case 3c, because the DD provides most of the ramping in Case 3c. The maximum range of dispatch is approximately $1.9 \mathrm{GW}$ in Case 2 and only $0.6 \mathrm{GW}$ in Case $3 \mathrm{c}$. In addition, the maximum capacity committed is nearly $2 \mathrm{GW}$ lower in Case $3 \mathrm{c}$ than it is in Case 2, and this reduction implies that the capital costs of maintaining system adequacy are lower. The corresponding results for natural gas generators are similar and the combination of 
oil and natural gas generators provides almost all of the ramping needed in Case 2 and only a small amount of the ramping needed in Case 3c. In contrast, the dispatch of baseload generators is constant in all system states over the 24 hours and is relatively unaffected when DD is added in Case 3c.

Figure 4: Hourly Ranges of Dispatches by Fuel type, Case 2 and Case 3c
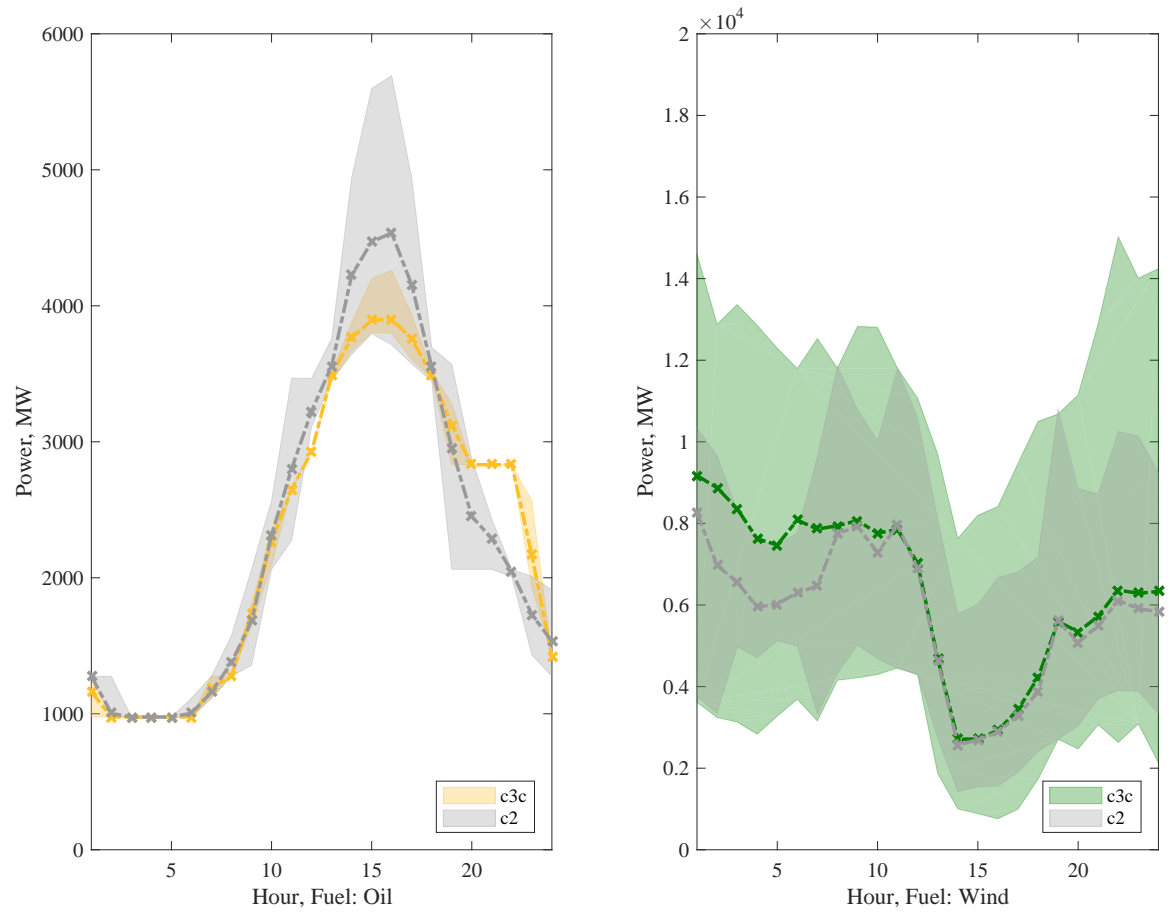

The second plot in Figure 4 shows the hourly ranges of wind generation in Case 2 (grey) and Case 3c (green), as well as the expected levels of generation (the solid lines marked by Xs). For most hours, the ranges in Case $3 \mathrm{c}$ are much larger than they are in Case 2, particularly for the maximum levels of generation at night. This implies that less of the potential wind generation is spilled when DD is available. The expected levels of generation in Case $3 \mathrm{c}$ are substantially higher at night and quite similar to Case 2 during the day. It should be noted that the larger ranges of wind generation in Case $3 c$ imply that more ramping is needed to maintain operating reliability. In spite of this, the amount of ramping supplied by the conventional generators is still much lower in Case $3 \mathrm{c}$ when DD is available.

\subsection{The Effects of Distributed Storage at Different Locations}

This section compares the use of TS at the two major population centers in our network, Boston and New York City. Table 5 summarizes the installed generating capacity at Bus 5 for the Boston area and Bus 19 for the New York City area. Because we are using a highly reduced network, many different generating units are clustered at the closest node. The generation portfolio for Boston is much more diverse than it is for New York City, and it includes nuclear and coal baseload capacity, natural gas and oil peaking capacity, and also wind capacity. In contrast, New York City only has natural gas and oil peaking capacity. The TS capacity at a node is proportional to its peak load, and the TS capacity of New York City is over three times larger than the TS capacity of Boston. 
Table 5: Summary of Generation Capacity for Boston and New York City (MW)

\begin{tabular}{llrr}
\hline & & Boston (Bus 5) & New York (Bus 19) \\
\hline Available Conventional Plants & Nuclear & 1,760 & 0 \\
& Coal & 706 & 0 \\
& NG & 2,544 & 7,103 \\
& Oil & 1,120 & 2,519 \\
\hline Wind Capacity (MW) & & 1,560 & 0 \\
Thermal Storage Capacity (MWh) & & 3,739 & 12,960 \\
\hline
\end{tabular}

Figure 5 shows the hourly expected generation by fuel type for the peak load day for Boston and New York City. In Boston, coal generators are the marginal units in the early hours and more expensive oil generators set the price during the peak hours. The lower prices available in the early morning provide an incentive to 'charge' the TS and increase the load and the TS is 'discharged' during the peak hours when prices are higher to reduce the load. In New York City, on the other hand, the oil generators set the price for most of the day. Even though the price incentives for shifting load from peak to off-peak hours are not as great in New York City, some of its TS capacity is still used to reduce the peak load.

\section{Figure 5: The Hourly Expected Dispatch (MWh) by Fuel Type for Case 3a in Boston and New York City}

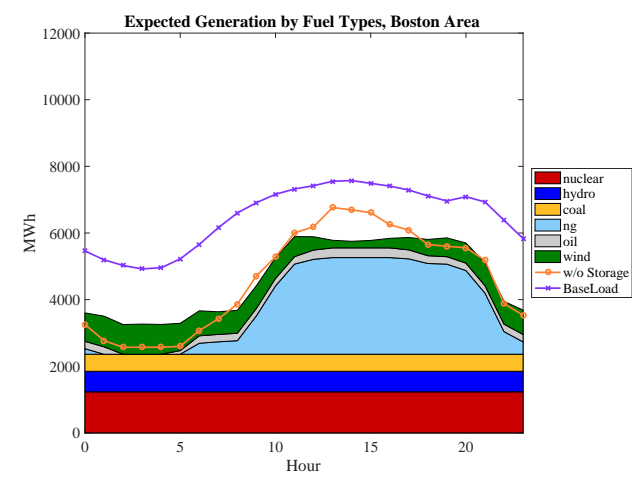

(a) Boston

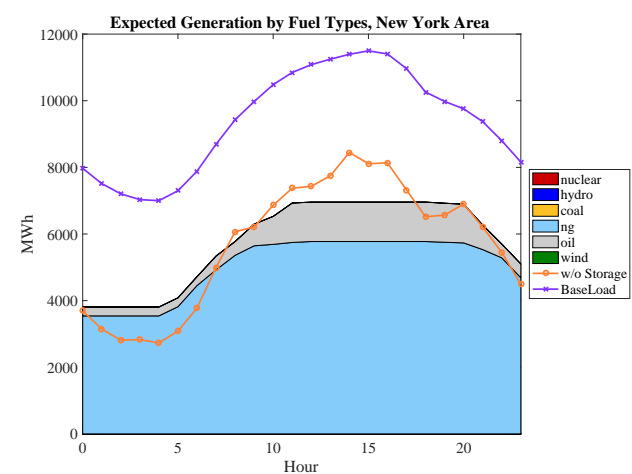

(b) New York City

Figure 5 also shows the total demand including both temperature and non-temperature sensitive demand (Baseload) and the total expected generation for Boston and New York City in Case 2 (w/o Storage) when there is no TS. Comparing this total with the total generation when there is TS in Case 3a shows that the TS reduces the generation at the peak and increases it off-peak. The reduced generation at the peak contributes to reducing the capital cost of the installed generating capacity needed for system adequacy shown in Table 4 The magnitudes of the reductions of generation at the peak are similar in Boston and New York City (982MW and 1,489MW, respectively) even though the capacity of TS is 3.5 times larger in New York City. The conclusion is that a higher proportion of the TS capacity is used to shift load in Boston than in New York City. This strategy is consistent with the hourly prices in the two locations shown in Figure 6 . The prices in New York City are relatively flat throughout the day compared to the prices in Boston, and as a result, there is less incentive for shifting load in New York City. These differences in price behavior are consistent with the generation profiles shown in Figure 5. The low prices off-peak in Boston are due to having enough wind and baseload generation at night to displace the more expensive peaking units. In New York City, the peaking units are dispatched all day. 
Figure 6: Hourly Prices (\$/MWh) for Cases 1-3 in Boston and New York City
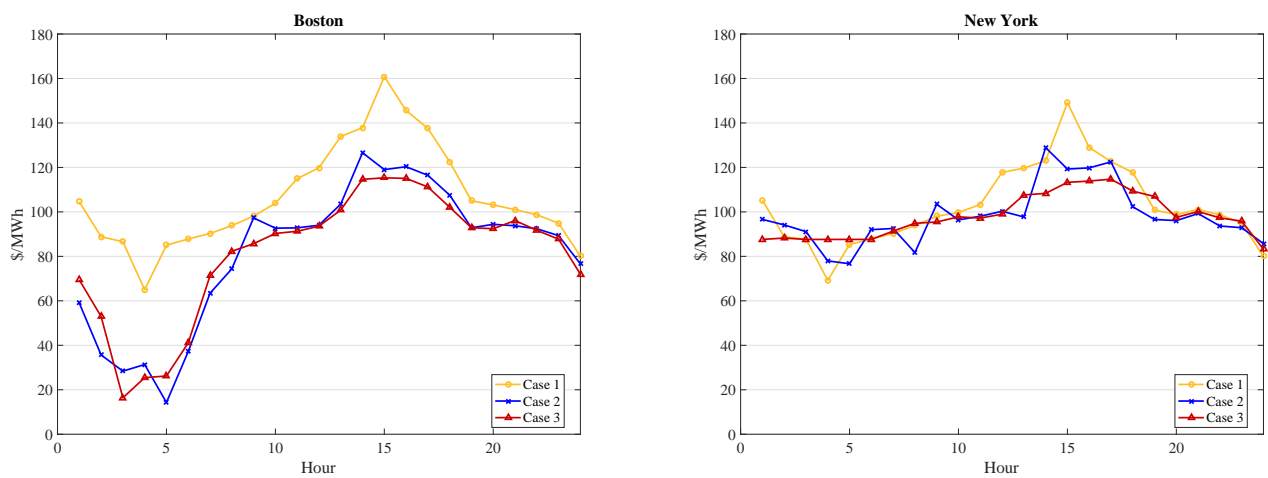

Table 6 summarizes the cost of generation and reserves in Boston and New York City for Case 2 with no TS and Case 3a with TS. In both locations, using TS significantly reduces the cost of reserves, particularly in New York City. The results also show reductions in the cost of generation in Boston due largely to the coupling between the wind generation there and the TS. Less potential wind generation is spilled when TS is available in Case 3a and the revenue for wind generation increases. The reduction in cost in Boston in Case 3a contrasts with the increased cost of generation in New York City. This increase is caused largely by the round-trip inefficiency of TS as well as the lack of wind generation. In other words, more electricity must be purchased in Case 3 a to provide the same level of cooling services as Case 2, and in Boston, the effect of spilling less wind is enough to offset the cost of purchasing more electricity.

Table 6: The Cost of Generation and Reserves (\$/day) for Cases 2 and 3a in Boston and New York City

\begin{tabular}{lrrrrrr}
\hline \multirow{2}{*}{ \$/day) } & \multicolumn{2}{c}{ Case 2} & & \multicolumn{2}{c}{ Case 3a } \\
\cline { 2 - 3 } \cline { 6 - 7 } & Boston & New York & & Boston & New York \\
\hline Cost of Generation & $4,063,365$ & $10,589,451$ & & $3,865,273$ & $11,656,776$ \\
Total Cost of Reserves & 321,041 & 305,270 & & 104,596 & 49,665 \\
Cost of LF Up Reserve & 136,306 & 123,457 & & 43,574 & 30,995 \\
Cost of LF Down Reserve & 117,632 & 114,609 & & 44,232 & 18,372 \\
Cost of Contingency Reserve & 67,102 & 67,204 & & 16,790 & 298 \\
\cline { 2 - 3 } Total Operating Cost & $4,384,406$ & $10,894,721$ & & $3,969,869$ & $11,706,440$ \\
\hline Revenue for Wind Generation & 538,878 & 0 & & 618,104 & 0 \\
\hline
\end{tabular}

The different strategies for managing TS implied by the results in Table 6 are illustrated in Figure 7 which shows the expected hourly levels of energy stored (solid black line) in Boston and New York City, as well as the maximum and minimum energy storage limits (dashed lines). The maximum expected amount of stored energy in Boston is approximately 90 percent of the available TS capacity, whereas the maximum in New York City is only 70 percent of the available TS capacity. If all of the capacity was used to shift load, the expected stored energy would increase to the maximum just before the peak period begins and then decline to zero by the end of the peak period. The fact that the expected stored energy is well within the physical limits of the TS implies that some of the capacity can be made available for ramping. The dotted lines $\left(S_{+}, S_{-}\right)$represent the maximum and minimum levels of stored energy that occurred in the different system states, and they show that both the physical limits are reached in some states in both Boston and New York City. The maximum limit 
is met when there is more wind generation than expected, and not discharging the TS is equivalent to increasing the load to replace the down-ramping provided by conventional generators. Similarly, having no stored energy occurs when there is less wind generation than expected and not charging the TS reduces the load and replaces the up-ramping provided by conventional generators. Since the range of the expected stored energy is smaller in New York City, a higher proportion of the TS capacity is available for ramping than it is in Boston.

Figure 7: Expected Hourly Energy Stored (percent) in Boston and New York City

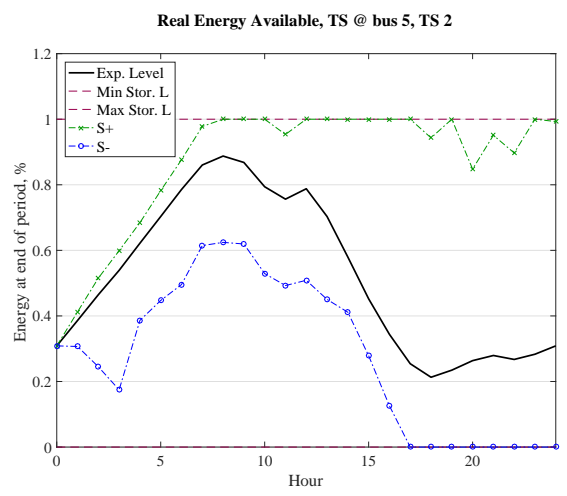

(a) Boston

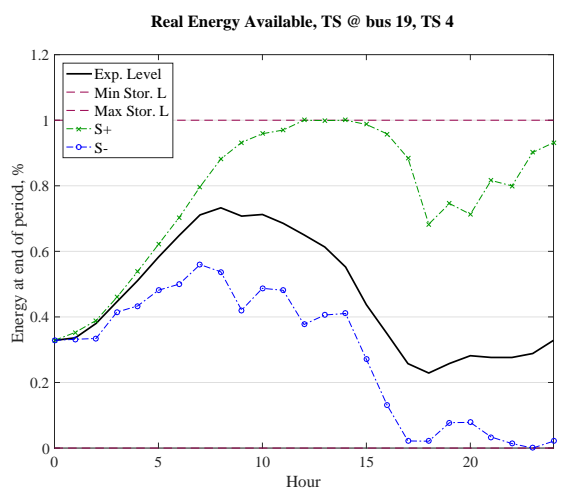

(b) New York

Table 7: The Revenue from Thermal Storage (\$/day) in Boston and New York City

\begin{tabular}{lrr}
\hline (\$/day) & Boston & New York \\
\hline Revenue from Shifting Load & 107,182 & 37,176 \\
Revenue from Lower Reserve Costs & 216,445 & 255,605 \\
\cline { 2 - 3 } Total Revenue & 323,627 & 292,781 \\
\hline Thermal Storage Capacity $(\mathrm{MWh})$ & 3,739 & 12,960 \\
Total Revenue $(\$ / \mathrm{MWh})$ & 86.6 & 22.6 \\
\hline
\end{tabular}

Figure 8 summarizes the results presented in Table 7 . The two columns measure the total revenue from TS for the two locations on the left axis, and the two lines measure the revenue per MWh from TS on the right axis. The total revenue for Boston is larger than it is for New York City due largely to the higher revenue from shifting load. Since the capacity of TS is 3.5 times larger in New York City, the total revenue per MWh for Boston is 3.8 times larger than it is for New York City. In terms of the savings in operating costs per MWh of storage capacity, the TS in Boston is much more valuable than it is in New York City.

The overall conclusion from comparing the different ways in which TS is used in Boston and New York City is that there are simple economic explanations for why shifting load is more important in Boston, why a large part of the TS capacity is used for ramping instead of shifting load in both locations, and why TS is more valuable per MWh in Boston. Table 7 provides the best summary of these economic results. Nevertheless, it is somewhat unsettling to take these results at their face value. Common sense suggests that reducing the peak load in New York City should be valuable because there is a lot of congestion on the grid at peak times and the corresponding prices in New York City can be substantially higher than they are in the rest of the region. The limited transmission capacity for supplying New York City makes it necessary to have a substantial amount of peaking capacity installed there. Typically, these peaking units have low capacity factors and are expensive to operate. 
Figure 8: Comparison of the Revenue Earned by Thermal Storage in Boston and New York City

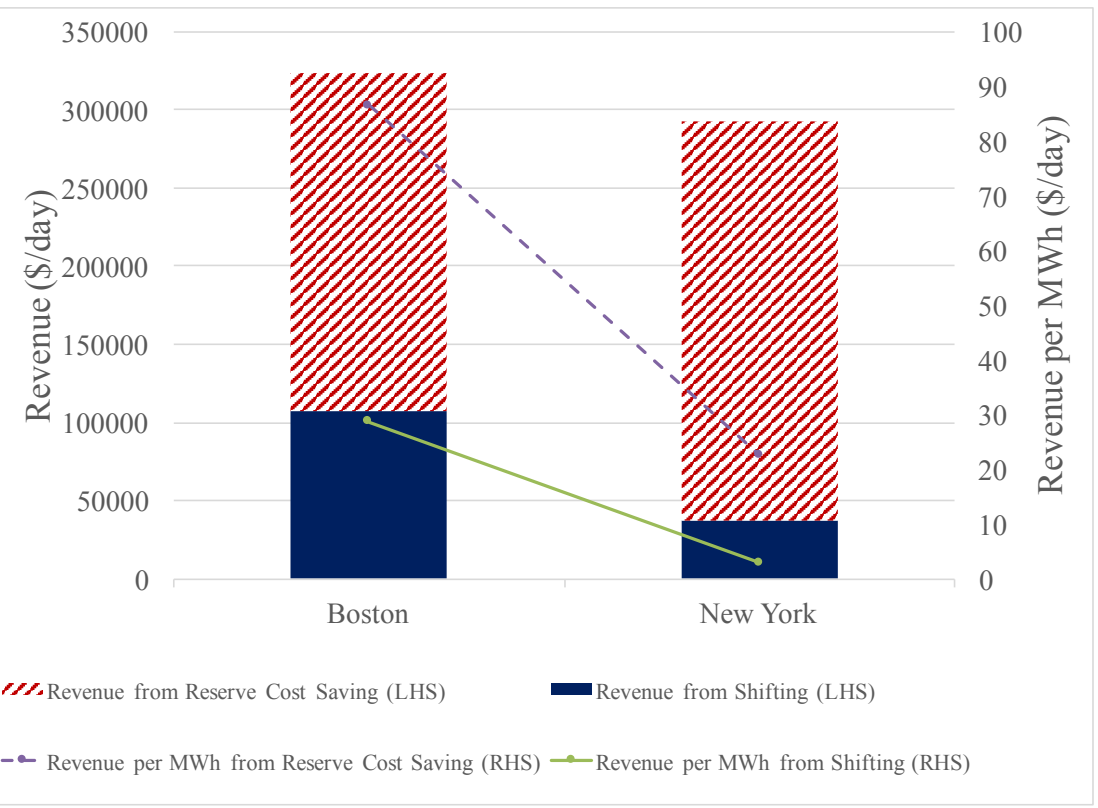

The basic cause of this economic paradox is that the objective used by a system operator to determine the optimum dispatch of generating units is to minimize the expected operating costs with no regard for improving the long-run economic efficiency by reducing capital costs. As a result, the incentive for shifting load must come entirely from the difference between the peak and off-peak prices, and as we have shown, this difference is small in New York City. These issues are discussed further in the concluding section.

\section{CONCLUSIONS}

The main objective of this paper is to evaluate the differences in the economic value of distributed storage (DD from TS and EVs) at different locations on a network that has a high penetration of wind generation. In order to do this type of analysis effectively, it is necessary to use a model that can represent the uncertainty associated with wind generation realistically, and also consider operations over a day to determine the optimal load shifting from managing the storage capacity. The analysis uses a stochastic form of multi-period Security Constrained Optimal Power Flow (SCOPF) that maximizes the expected social surplus for operations over a 24-hour period. This model assumes implicitly that a system operator determines how all generating capacity is committed and the charging/discharging profiles of DD. The analysis is based on a reduced network representing New York State and New England for five cases with different specifications about the amount of wind capacity and the type of DD that is available.

The results for the peak load hour in Table 3 show, as expected, that adding wind generation displaces conventional generation (by 4.5 percent). However, the reduction in the total amount of conventional generating capacity committed at the peak is much smaller (only 2.7 percent) because a lot more conventional capacity is committed for ramping reserves. When DD is added, the economic benefits of managing TS and EVs optimally are to reduce the expected operating costs by (1) spilling less of the potential wind generation, and therefore, reducing the generation from conventional sources, and (2) providing ramping services to the grid to reduce the amount of conventional reserve capacity purchased. TS can further reduce system costs by shifting some load from peak to off-peak hours and reducing the amount of installed conventional capacity needed at the peak to maintain operating 
reliability. In fact, this additional reduction of the peak load from adding TS is over three times larger than the initial reduction from adding wind generation. This type of load shifting with TS is not possible with EVs in our analysis because we assume that vehicle-to-grid capabilities are not supported. It should be noted that even though the cooling services delivered remain exactly the same when TS is added, more energy is purchased from the grid over the day with TS due to the round-trip inefficiency of storage (i.e., the energy in is greater than the energy out).

The incremental capital costs of adding TS and EVs in different cases are compared in Table 4 together with the corresponding savings in the capital cost of the installed conventional generating capacity needed to maintain system adequacy. The incremental capital cost of adding TS is less than half of the capital costs saved from reducing the amount of installed conventional capacity needed. In contrast, adding EVs does not reduce the amount of conventional capacity needed, and as a result, there are no savings to offset the capital cost of the expensive battery. The economic justification for having an EV would depend, to a large extent, on spending less on gasoline rather than on reducing the total cost of generating electricity. The overall conclusion is that an important economic benefit from adding TS comes from reducing the capital cost of conventional generating capacity as well as from spilling less wind generation and reducing ramping costs. The results presented so far confirm results that we have presented in other publications (Lamadrid et al. 2014).

The new material in this paper determines and explains the differences in the use and value of DD in two major demand centers, Boston and New York City. These two centers have very different mixtures of generating capacity installed at their nodes. Boston has a combination of baseload units, peaking units and wind capacity for a total of $6 \mathrm{GW}$, but New York City simply has $9.5 \mathrm{GW}$ of oil and natural gas peaking units. Generally, the locally installed generating units set the prices at the two locations, particularly when the system load is high and there is congestion on the grid. The comparison of the values of DD at the two locations is based on DD from TS only, and the amount of TS installed is proportional to the load at each location. Consequently, the capacity of TS in New York City is 3.5 times larger than the capacity of TS in Boston, but in spite of this difference, the reduction of the peak load from adding DD is only 1.5 times larger than the reduction in Boston. Furthermore, the daily revenue earned by TS from shifting load in New York City (i.e., by replacing the purchases of expensive energy at the peak with less expensive purchases off-peak) is only one third of the corresponding revenue in Boston even though the physical amount of load shifted is larger. The main reason for the low revenue from shifting load in New York City is that peaking units set the hourly prices all day and the range of hourly prices over the day is relatively small compared to Boston. In Boston, the prices are set by peaking units during the day and by baseload units at night.

The other source of revenue earned by TS comes from reducing the amount of conventional capacity purchased for ramping reserves. This source of revenue is slightly larger in New York City than it is in Boston, but in both locations, it is substantially larger than the revenue from shifting load (twice as large in Boston and nearly seven times larger in New York City). The basic economic tradeoff is between the certain cost of purchasing more conventional reserve capacity for ramping and the savings in operating costs from spilling less of the potential wind generation in relatively low-probability states when the level of wind generation is higher than expected. The TS simply provides a less expensive way to provide ramping than conventional capacity, and the main cost of using TS for ramping comes from the round-trip inefficiency of storing energy.

When the revenues from shifting load and reducing reserve costs are combined, the total revenue in Boston is larger than it is in New York City. Since the capacity of TS in New York City is 3.5 times larger than it is in Boston, the revenue per MWh of storage capacity is much larger in Boston than New York City (3.8 times larger). In this sense, the storage capacity in Boston is substantially more valuable than it is in New York City, but this conclusion is only correct if one ignores the implications for long-run economic efficiency and the capital costs of installed conventional capacity. The system operator determines the optimum commitment of generating units for dispatch and reserves and the charging and discharging of TS by minimizing the expected daily operating cost of meeting the energy 
needs of customers and maintaining operating reliability. The lack of major price differences between peak and off-peak periods in New York City was why so much of the TS there was used to provide ramping rather than to shift load. Since the standard planning goal for a network is to have enough installed generating capacity to meet the peak system load and cover n- 1 contingencies, reducing the system peak implies that less installed generating capacity is needed, leading to lower capital costs. In our empirical example, the savings in the capital cost of installed conventional capacity was twice as large as the incremental cost of installing TS. Since TS also reduced the expected operating costs, adding TS proved to be an effective way to improve both the short-run and long-run economic efficiency and still supply the energy needs of customers and maintain operating reliability.

The overall conclusion is that minimizing the expected operating costs on peak load days is likely to lead to a sub-optimal solution because the effects of load shifting are under-valued. The amount of load shifting from DD that occurs on a peak-load day at a specific location is highly idiosyncratic and depends on the type of local resources that are available there. In terms of reducing the total system cost, reducing the peak load at load centers, like New York City, that are isolated by congestion on the grid is likely to have a substantial payoff even if the revenue per MWh from DD is small. In fact, we have shown in Lamadrid et al. (2014) that using DD to lower the peak load in a congested load center is an effective substitute for upgrading transmission. Consequently, we conclude that there is a sound economic rationale for introducing some form of peak-load pricing into the system operator's optimizing criterion. The decision to do this could be made public by the system operator a day in advance, based on the forecast of the peak load on the following day. For example, if the forecasted peak is greater than a target level set by regulators, peak-load pricing would be implemented on the next day. Determining the best way to implement such a policy will be the subject of new research. Although we have analyzed peak-load pricing in an earlier paper (Lamadrid et al. 2015b), the procedures we considered were not very effective. There is a lot of room for improvement.

\section{ACKNOWLEDGEMENTS}

This research was supported by the Lehigh Faculty Innovation Grant and the National Science Foundation through the CyberSEES grant \#1442858. We thank Ray Zimmerman, Carlos E. MurilloSánchez, Richard E. Schuler, C. Lindsay Anderson and Robert J. Thomas for their inputs to this work. The authors are responsible for all conclusions presented in the paper and the views expressed have not been endorsed by the sponsoring agencies.

\section{REFERENCES}

Agan, D., P. Besuner, P. Grimsrud and S. Lefton (2008). Cost of Cycling Analysis For Pawnee Station. Tech. rep., Aptech.

Allen, E., J. Lang and M. Ilic (2008). A Combined Equivalenced-electric, Economic, and Market Representation of the Northeastern Power Coordinating Council U.S. Electric Power System. Power Systems, IEEE Transactions on 23 (3), 896-907.

Arroyo, J. and F. Galiana (2005). Energy and Reserve Pricing in Security and Network-Constrained Electricity Markets. Power Systems, IEEE Transactions on 20 (2), 634-643.

Bertsimas, D., E. Litvinov, X. Sun, J. Zhao and T. Zheng (2013). Adaptive Robust Optimization for the Security Constrained Unit Commitment Problem. Power Systems, IEEE Transactions on 28 (1), 52-63.

Borenstein, S. (2005). The Long-Run Efficiency of Real-Time Electricity Pricing. The Energy Journal 26 (3), 93-116.

Borenstein, S. (2007). Customer Risk from Real-Time Retail Electricity Pricing: Bill volatility and hedgability. The Energy Journal 28 (2), 111-130.

Bushnell, J., B. F. Hobbs and F. A. Wolak (2009). When It Comes To Demand Response, Is FERC Its Own Worst Enemy? The Electricity Journal 22 (8), $9-18$. URL http://www.sciencedirect.com/science/article/pii/S104061900900219X

Callaway, D. and I. Hiskens (2011). Achieving Controllability of Electric Loads. Proceedings of the IEEE 99 (1), $184-199$.

Chen, X. and A. N. Kleit (2016). Money for Nothing?: Why FERC Order 745 Should Have Died. The Energy Journal 37 (2), 
201-221.

URL http://www.iaee.org/en/publications/ejarticle.aspx?id=2758

Cuomo, A. (2014). Governor Cuomo Announces Fundamental Shift in Utility Regulation. Tech. rep., State of New York, Executive Chamber. URL http://www.governor.ny.gov/press/04242014Utility-Regulation

Davis, S., S. Diegel and R. Boundy (2013). Transportation Energy Data Book. U.S. Department of Energy, Oak Ridge, TN. URL/http://www-cta.ornl.gov/data/index.shtml

Denholm, P., J. Jorgenson, M. Hummon, T. Jenkin and D. Palchak (2013). The Value Of Energy Storage For Grid Applications. Tech. rep., National Renewable Energy Laboratory. URL http://www.nrel.gov/docs/fy13osti/58465.pdf

EAC (2008). Bottling Electricity: Storage As A Strategic Tool For Managing Variability And Capacity Concerns In The Modern Grid. Tech. rep., Electricity Advisory Committee.

EIA (2016). Updated Capital Cost Estimates For Utility Scale Electricity Generating Plants. Tech. rep., EIA. URL https://www.eia.gov/analysis/studies/powerplants/capitalcost/

EIA, C. B. (2017). EIA's Residential And Commercial Studies Require Significant Data Collection And Analysis. Tech. rep., EIA. URL http://www.eia.gov/todayinenergy/detail.php?id=29852\&src=email

EIA, J. M. (2015). EIA's CBECS Is The Nation's Only Comprehensive Survey Of Commercial Buildings. Tech. rep., EIA. URL http://www .eia.gov/todayinenergy/detail.cfm?id=21112\&src=email

EPRI (2001)a. Correlating Cycle Duty With Cost At Fossil Fuel Power Plants. Tech. rep., Electric Power Research Institute. EPRI (2001)b. Damage To Power Plants Due To Cycling. Tech. rep., Electric Power Research Institute.

EVAPCO (2007). Thermal Ice Storage - Application And Design Guide. Tech. rep., EVAPCO, Inc.

Faruqui, A., S. Sergici and L. Akaba (2014). The Impact of Dynamic Pricing on Residential and Small Commercial And Industrial Usage: New Experimental Evidence From Connecticut. Energy Journal 35 (1), 137-160. URL http://search . ebscohost . com/login . aspx?direct=true\&db=asm\&AN=92982505\&site=ehost-live

Forbes, K. F. and E. M. Zampelli (2014). Are German Policymakers Adequately Apprised about the Challenges posed by Large-Scale Integration of Renewable Energy into the Electric Power System? Tech. rep., The Catholic University of America.

Guan, Y. and M. Kezunovic (2013). Contingency-Based Nodal Market Operation Using Intelligent Economic Alarm Processor. Smart Grid, IEEE Transactions on 4 (1), 540-548.

Hirth, L. (2015). The Optimal Share of Variable Renewables: How the Variability of Wind and Solar Power Affects their Welfare-Optimal Deployment. The Energy Journal 36 (1), 127-162.

Hobbs, B. F. (1991). The "Most Value" Test: Economic Evaluation Of Electricity Demand-Side Management Considering Customer Value. The Energy Journal 12 (2), 67-91. URL http://www.jstor.org.proxy.library.cornell.edu/stable/41322416

Hunt, M., K. Heinemeier, M. Hoeschele and E. Weitzel (2010). HVAC Energy Efficiency Maintenance Study. Tech. rep., CALMAC.

Jeon, W., A. Lamadrid, J. Mo and T. Mount (2015). Using Deferrable Demand in a Smart Grid to Reduce the Cost of Electricity for Customers. Journal of Regulatory Economics, 1-34. URL http://dx.doi.org/10.1007/s11149-015-9268-0

Keller, J., D. Manz and S. Taub (2008). Grid Scale Energy Storage. Tech. rep., General Electric.

Kraning, M., E. Chu, J. Lavaei and S. Boyd (2014). Dynamic Network Energy Management Via Proximal Message Passing. Foundations and Trends ${ }^{\circledR}$ in Optimization 1 (2), 73-126. URL http://dx.doi.org/10.1561/2400000002

Kumar, N., P. M. Besuner, S. A. Lefton, D. D. Agan and D. D. Hilleman (2012). Power Plant Cycling Costs. Tech. rep., Intertek APTECH. URL http://wWw.nrel.gov/docs/fy12osti/55433.pdf

Lamadrid, A., T. Mount, W. Jeon and H. Lu (2015). Is Deferrable Demand an Effective Alternative to Upgrading Transmission Capacity? Journal of Energy Engineering, B4014005. URL http://dx.doi.org/10.1061/(ASCE)EY.1943-7897.0000182

Lamadrid, A., D. Shawhan, C. Murillo-Sanchez, R. Zimmerman, Y. Zhu, D. Tylavsky, A. Kindle and Z. Dar (2015). Stochastically Optimized, Carbon-Reducing Dispatch of Storage, Generation, and Loads. Power Systems, IEEE Transactions on 30 (2), 1064 - 1075.

Lamadrid, A. J., Jeon, W.-Y., Mount, T. D., 2015b. Can pay-for-performance pricing help to manage deferrable demand more efficiently during peak load periods? In: Rutgers 34th Annual Eastern Conference. 
Lamadrid, A. J., T. Mount and R. Zimmerman (2013). On The Capacity Value of Renewable Energy Sources in the Presence of Energy Storage and Ramping Constraints. In: Modeling and Simulation of Cyber-Physical Energy Systems (MSCPES), 2013 Workshop on. pp. 1-7.

Lawton, L., M. Sullivan, K. Van Liere, A. Katz and J. Eto (2003). A Framework and Review of Customer Outage Costs: Integration and Analysis of Electric Utility Outage Cost Surveys. Tech. rep., U.S. Department of Energy, Washington DC.

Lefton, S. A. and D. D. Hilleman (2011). Make Your Plant Ready for Cycling Operations. Power 155 (8). URL http://www. powermag.com/gas/3885.html

Lew, D., G. Brinkman, N. Kumar, P. Besuner, D. Agan and S. Lefton (2012). Impacts of Wind and Solar on Emissions and Wear-and-Tear of Fossil-Fueled Generators. In: Power and Energy Society General Meeting, 2012 IEEE. pp. 1-8.

Mass. Div. (2000). Installation Guide for Electric Vehicle Charging Equipment. Tech. rep., The Massachusetts Division of Energy Resources. URL http://www.mass.gov/eea/docs/doer/alternative-fuels/ev-manual-mass-32011.pdf

Murillo-Sanchez, C., R. Zimmerman, C. Anderson and R. Thomas (2013). Secure Planning and Operations of Systems with Stochastic Sources, Energy Storage, and Active Demand. Smart Grid, IEEE Transactions on 4 (4), 2220-2229.

NERC (2017). Reliability Standards for the Bulk Electric Systems of North America. North American Electric Reliability Corporation, 3353 Peachtree Road NE Suite 600, North Tower, Atlanta, GA 30326. URL http://wwW.nerc.com/pa/Stand/Reliability\%20Standards\%20Complete\%20Set/RSCompleteSet.pdf

NREL (2010). Eastern Wind Integration and Transmission Study. Tech. rep., EnerNex Corporation, The National Renewable Energy Laboratory, 1617 Cole Boulevard, Golden, Colorado 80401.

Palensky, P. and D. Dietrich (2011). Demand Side Management: Demand Response, Intelligent Energy Systems, and Smart Loads. Industrial Informatics, IEEE Transactions on 7 (3), 381-388.

Parkinson, G. (2017). Tesla Big Battery Outsmarts Lumbering Coal Units After Loy Yang Trips. Reneweconomy. URLhttp://reneweconomy.com.au/tesla-big-battery-outsmarts-lumbering-coal-units-after-loy-yang-trips-70003/

Parsons, Brinckerhoff Quade and Douglas (2000). Regional Travel - Household Interview Survey. Tech. rep., The New York Metropolitan Transportation Council, the North Jersey Transportation Planning Authority. URL http://www.njtpa.org/datamap/Perf/HIS/documents/exsum00321.pdf

Pourmousavi, S., Patrick, S., Nehrir, M. (2014). Real-Time Demand Response Through Aggregate Electric Water Heaters for Load Shifting and Balancing Wind Generation. Smart Grid, IEEE Transactions on 5 (2), 769-778.

Queiroz, C., A. Mahmood and Z. Tari (2013). A Probabilistic Model to Predict the Survivability of SCADA Systems. Industrial Informatics, IEEE Transactions on 9 (4), 1975-1985.

Rahimi, F. and A. Ipakchi (2010). Demand Response as a Market Resource Under the Smart Grid Paradigm. Smart Grid, IEEE Transactions on 1 (1), $82-88$.

RTO Insider (2016). FERC Rule Would Boost Energy Storage. Tech. rep. URL https://www.rtoinsider.com/ferc-rule-boost-energy-storage-der-34469/

Siano, P., C. Cecati, H. Yu and J. Kolbusz (2012). Real Time Operation of Smart Grids Via FCN Networks And Optimal Power Flow. Industrial Informatics, IEEE Transactions on 8 (4), 944-952.

Simshauser, P. and D. Downer (2016). On the Inequity of Flat-Rate Electricity Tariffs. The Energy Journal 37 (3), 199-229. URL http://www .iaee.org/en/publications/ejarticle.aspx?id=2782

Sioshansi, R. and P. Denholm (2010). The Value of Plug-In Hybrid Electric Vehicles as Grid Resources. The Energy Journal $31(3), 1-23$. URL http://ideas.repec.org/a/aen/journl/2010v31-03-a01.html

Valentine, K., W. G. Temple and K. M. Zhang (2011). Intelligent Electric Vehicle Charging: Rethinking the Valley-Fill. Journal of Power Sources 196 (24), 10717 - 10726. URL http://wwW.sciencedirect.com/science/article/pii/S0378775311016223

Wang, B. and B. F. Hobbs (2016). Real-Time Markets for Flexiramp: A Stochastic Unit Commitment-Based Analysis. IEEE Transactions on Power Systems 31 (2), 846-860.

Warrington, J., P. Goulart, S. Mariethoz and M. Morari (2012). Robust Reserve Operation In Power Systems Using Affine Policies. In: Decision and Control (CDC), 2012 IEEE 51st Annual Conference on. pp. 1111-1117.

Wirl, F. (2000). Lessons from Utility Conservation Programs. The Energy Journal 21 (1), 87-108. URL http://www . jstor.org.proxy.library.cornell.edu/stable/41322856

Woo, C.K. and D. Q. Seeto (1988). Optimal Off-Peak Incremental Sales Rate Design in Electricity Pricing. The Energy Journal 9 (1), 95-102. URL http://www.jstor.org.proxy.library.cornell.edu/stable/41969147

Fung, B. (2017). Tesla's enormous battery in Australia, just weeks old, is already responding to outages in 'record' time. Washington Post.

Copyright (C) 2016 by the IAEE. All rights reserved. 
Xu, L., J. Liu, J. Pei and X. Han (2013). Building Energy Saving Potential in Hot Summer and Cold Winter (HSCW) zone, China-Influence of Building Energy Efficiency Standards and Implications. Energy Policy 57 (2013), 253-262.

URL http://www.sciencedirect.com/science/article/pii/S030142151300075X

You, J.S. and S.Y. Lim (2017). Welfare Effects of Nonlinear Electricity Pricing. The Energy Journal 38 (1), 195-211.

URL http://www . iaee.org/en/publications/ejarticle. aspx?id=2857

Zhou, Z., T. Levin and G. Conzelmann (2016). Survey of U.S. Ancillary Services Markets. Tech. rep., Argonne National

Lab.(ANL).

URL http://www.ipd.anl.gov/anlpubs/2016/01/124217.pdf

\section{A. MODEL FORMULATION}

A simplified formulation of our model is presented in this section. The notation is defined in Table 8 For a full description of the model, refer to Lamadrid et al. (2015) and Murillo-Sanchez et al. (2013).

\section{Table 8: Definition of indices, functions and parameters}

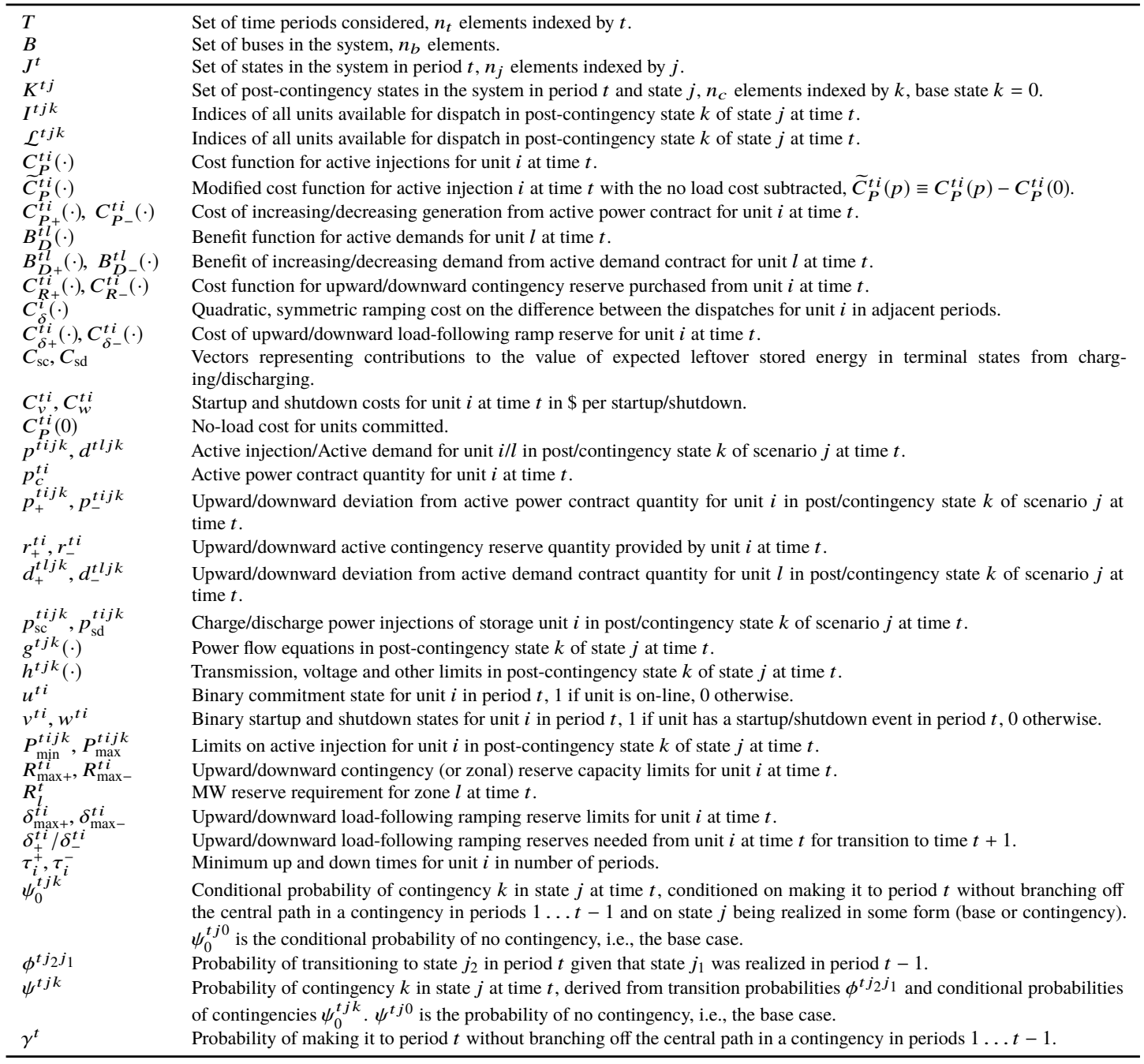

The problem is formulated as a minimization of the expected total system costs.

$$
\begin{aligned}
\min f(x) & =f_{p}\left(p, p_{+}, p_{-}\right)+f_{d}\left(d, d_{+}, d_{-}\right)+f_{r}\left(r_{z}, r_{+}, r_{-}\right)+f_{\delta}(p) \\
& +f_{\mathrm{lf}}\left(\delta_{+}, \delta_{-}\right)+f_{s}\left(p_{\mathrm{sc}}, p_{\mathrm{sd}}\right)+f_{\mathrm{uc}}(v, w),
\end{aligned}
$$


where,

$$
\begin{gathered}
f_{p}\left(p, p_{+}, p_{-}\right)=\sum_{t \in T} \sum_{j \in J^{t}} \sum_{k \in K^{t j}} \psi^{t j k} \sum_{i \in I^{t j k}}\left(\widetilde{C}_{P}^{t i}\left(p^{t i j k}\right)\right. \\
\left.+C_{P+}^{t i}\left(p_{+}^{t i j k}\right)+C_{P-}^{t i}\left(p_{-}^{t i j k}\right)\right), \\
f_{d}\left(d, d_{+}, d_{-}\right)=\sum_{t \in T} \sum_{j \in J^{t}} \sum_{k \in K^{t j}} \psi^{t j k} \sum_{l \in \mathcal{L}^{t j k}}\left(B_{D}^{t l}\left(d^{t l j k}\right)\right. \\
\left.+B_{D+}^{t l}\left(d_{+}^{t l j k}\right)+B_{D-}^{t l}\left(d_{-}^{t l j k}\right)\right), \\
f_{r}\left(r_{+}, r_{-}\right)=\sum_{t \in T} \gamma^{t} \sum_{i \in I^{t}}\left[C_{R+}^{t i}\left(r_{+}^{t i}\right)+C_{R-}^{t i}\left(r_{-}^{t i}\right)\right], \\
f_{\delta}(p)=\sum_{t \in T} \gamma^{t} \sum_{j_{1} \in J^{t-1}} \phi^{t j_{2} j_{1}} \sum_{i \in I^{t j_{2} 0}} C_{\delta}^{i}\left(p^{t i j_{2} 0}-p^{(t-1) i j_{1} 0}\right), \\
f_{\mathrm{uc}}(v, w)=\sum_{t \in T} \gamma^{t} \sum_{i \in I^{t}}\left(C_{P}^{t i}(0) u^{t i}+C_{v}^{t i} v^{t i}+C_{w}^{t i} w^{t i}\right) . \\
f_{\mathrm{lf}}\left(\delta_{+}, \delta_{-}\right)=\sum_{t \in T} \gamma^{t} \sum_{i \in I^{t}}\left[C_{\delta+}^{t i}\left(\delta_{+}^{t i}\right)+C_{\delta-}^{t i}\left(\delta_{-}^{t i}\right)\right], \\
f_{s}\left(p_{\mathrm{sc}}, p_{\mathrm{sd}}\right)=-\left(C_{\mathrm{sc}}^{\top} p_{\mathrm{sc}}+C_{\mathrm{sd}}^{\top} p_{\mathrm{sd}}\right),
\end{gathered}
$$

subject to:

- full set of equality constraints

$$
g^{t j k}\left(\theta^{t j k}, p^{t j k}\right)=0
$$

- set of operational inequality constraints

$$
h^{t j k}\left(\theta^{t j k}, p^{t j k}\right) \leq 0
$$

- set of constraints for re-dispatching and deviations from contracts for all generators and demand, e.g.,

$$
p^{t i j k}-p_{c}^{t i}=p_{+}^{t i j k}-p_{-}^{t i j k}
$$


- ramping limits for contingencies, i.e., low probability events, e.g.,

$$
0 \leq r_{+}^{t i} \leq R_{\max +}^{t i}, \quad 0 \leq r_{-}^{t i} \leq R_{\max -}^{t i}
$$

- ramping limits for load following, i.e., high probability events, e.g.,

$$
\begin{aligned}
& 0 \leq \delta_{+}^{t i} \leq \delta_{\max +}^{t i}, \quad 0 \leq \delta_{-}^{t i} \leq \delta_{\max -}^{t i} \\
& \quad p^{(t-1) i j_{1} 0}-p^{t i j_{2} 0} \leq \delta_{-}^{(t-1) i}, \quad j_{1} \in J^{t-1}, j_{2} \in J^{t}
\end{aligned}
$$

- limits on the storage units, e.g.,

$$
p^{t i j k}=p_{\mathrm{sc}}^{t i j k}+p_{\mathrm{sd}}^{t i j k}
$$

- constraints related to unit commitment, e.g.,

$$
\sum_{y=t-\tau_{i}^{+}}^{t} v^{y i} \leq u^{t i}, \quad \sum_{y=t-\tau_{i}^{-}}^{t} w^{y i} \leq 1-u^{t i}
$$

